\title{
Enhancement on the Tribological Properties of the Multilayer RGO/Al Matrix Composites by Cu-Coating Method
}

\author{
Fengguo Liu ${ }^{1,2}$, Ning Su ${ }^{1}$ and Renguo Guan ${ }^{1, *}$ \\ 1 School of Materials and Metallurgy, Northeastern University, Shenyang 110004, China; \\ liufg@sylu.edu.cn (F.L.); ningsu@sjtu.edu.cn (N.S.) \\ 2 School of Materials Science and Engineering, Shenyang Ligong University, Shenyang 110004, China \\ * Correspondence: guanrg@smm.neu.edu.cn; Tel.: +86-24-8368-1463
}

check for updates

Citation: Liu, F.; Su, N.; Guan, R. Enhancement on the Tribological Properties of the Multilayer RGO/Al Matrix Composites by Cu-Coating Method. Materials 2021, 14, 3163. https://doi.org/10.3390/ ma14123163

Academic Editor: Ştefan Ţălu

Received: 17 April 2021

Accepted: 5 June 2021

Published: 9 June 2021

Publisher's Note: MDPI stays neutral with regard to jurisdictional claims in published maps and institutional affiliations.

Copyright: (c) 2021 by the authors. Licensee MDPI, Basel, Switzerland. This article is an open access article distributed under the terms and conditions of the Creative Commons Attribution (CC BY) license (https:// creativecommons.org/licenses/by/ $4.0 /)$.

\begin{abstract}
Multilayer reduced graphene oxide (mrGO) was chemically modified by electroless plating of copper on surface to form mrGO-Cu. The scanning electron microscope (SEM) and transmission electron microscope (TEM) analysis revealed that nano-Cu particles were uniformly dispersed on the surface of mrGO. The mrGO-Cu powders were further utilized as reinforcements for aluminum (Al) matrix and the mrGO-Cu/Al composite was successfully fabricated through clad rolling of milled powder. The tribological properties of the mrGO-Cu/Al composites were explored. The tribological results show that the mrGO-Cu could reduce the friction coefficient and wear loss of mrGO-Cu/Al composites, since the mrGO-Cu participated in lubricating processes due to the formation of a transfer layer on the contact surface. Furthermore, it is found that the composition of mrGO-Cu could significantly influence the tribological properties of the mrGO-Cu/Al composites. The composites with $4 \%$ of mrGO-Cu for composites exhibited the best tribological behavior, which transformed from adhesive wear to abrasive wear, due to the formation of a graphite lubricating film.
\end{abstract}

Keywords: multilayer reduced graphene oxide; tribological properties; aluminum matrix composites

\section{Introduction}

Aluminum and aluminum alloys have been widely used as light structural materials in aerospace, automotive and machinery manufacturing engineering as well as in other fields, due to their outstanding properties, such as high specific strength and good ductility [1]. However, the adhesiveness of aluminum composites may cause poor wear properties, which is a significant problem for the fabrication and application of the composites. Many efforts have been made to improve the abrasive resistance of Al-based composites [2-4].

As carbon materials can lead to a conformal protective coating on the sliding contact interfaces owing to low shear stress of C-C layer and self-lubricating property, reinforcing aluminum composites with carbon materials is regarded as an effective way to improve its abrasive resistance performance. Various types of carbon materials, such as carbon nanotubes, carbon fiber and graphite, have been applied as the reinforcements in aluminum alloy to improve their wear properties [5-7].

Since graphene was fabricated and observed by UK Geim and Novoselov by micromechanical exfoliation method on graphite, its excellent physical and electrical properties have been widely explored in science and industry [8-12]. Recently, many literatures showed that graphene could be used as reinforcements to improve the wear resistance of composites [13-16]. For example, Han Wang et al. [17] found that the tribological performance of poly vinyl chloride (PVC) composites could be improved obviously through adding multi-layer graphene (MLG), due to the enhanced toughness of the MLG/PVC composites and high self-lubricant properties of the MLG. Manuel Belmonte et al. [18] revealed that graphene nanoplatelets can enhance the tribological performance of ceramics due to the exfoliation of nanoplatelets that creates an adhered protective tribo-film. Jian Xuezhen et al. [19] revealed that the addition of graphene changed the wear mode of 
graphene/PTEE composites from adhesive wear to a mechanism of adhesive wear and abrasive wear. Zhang Yubing et al. [20] found that wear resistance of $\mathrm{Si}_{3} \mathrm{~N}_{4}$ could be improved through adding graphene. Most of the recent studies on graphene reinforcing tribological properties focused on organic polymer and ceramics [21-26], but there are few reports on tribological properties of metal-based composites reinforced by graphene such as aluminum composites.

In this work, we tried to explore the effect of graphene on enhancing the tribological properties of aluminum. The multilayer reduced graphene oxide was chemically modified by electroless $\mathrm{Cu}$ plating, aiming to improve the wettability between aluminum and graphene. Expectedly, the mrGO-Cu/Al composite was successfully fabricated through clad rolling of milled powder. Moreover, the influence of mrGO-Cu on the tribological properties of mrGO-Cu/aluminum composites, as well as its wear behavior and wear mechanism, were investigated in detail.

\section{Materials and Methods}

\subsection{Materials and Preparation}

Pure aluminum power $(\geq 99.5 \%)$ with an average particle diameter of $20 \mu \mathrm{m}$ was used as the matrix. Multilayer reduced graphene oxide was prepared by Hummers method, and then modified with copper using an electroless Cu plating method [27]. Figure 1 shows the Fourier transform infrared spectroscopy (FTIR) results of the GO and mrGO. There were residual functional groups $\mathrm{C}-\mathrm{O}-\mathrm{C}$ in $\mathrm{mrGO}$. Aluminum and mrGO-Cu powders were mixed for $1 \mathrm{~h}$ in alcohol solvent. Then, the mixed powder was vacuum dried for $12 \mathrm{~h}$. The dried mixed powder was ball milled for another $30 \mathrm{~min}$, and the ball-to-battery ratio was 7:1. Then, the homogeneous mixture was placed into aluminum tubes ( $48 \mathrm{~mm}$ in diameter), headed to $500{ }^{\circ} \mathrm{C}$ and incubated for $3 \mathrm{~h}$. After that, the mixed powders were rolled with a deformation of $60-70 \%$ to obtain the mrGo- $\mathrm{Cu} / \mathrm{Al}$ composite sheets. Finally, the composites were exposed by removing the surface aluminum layers. The pure aluminum specimen was prepared in the same way.

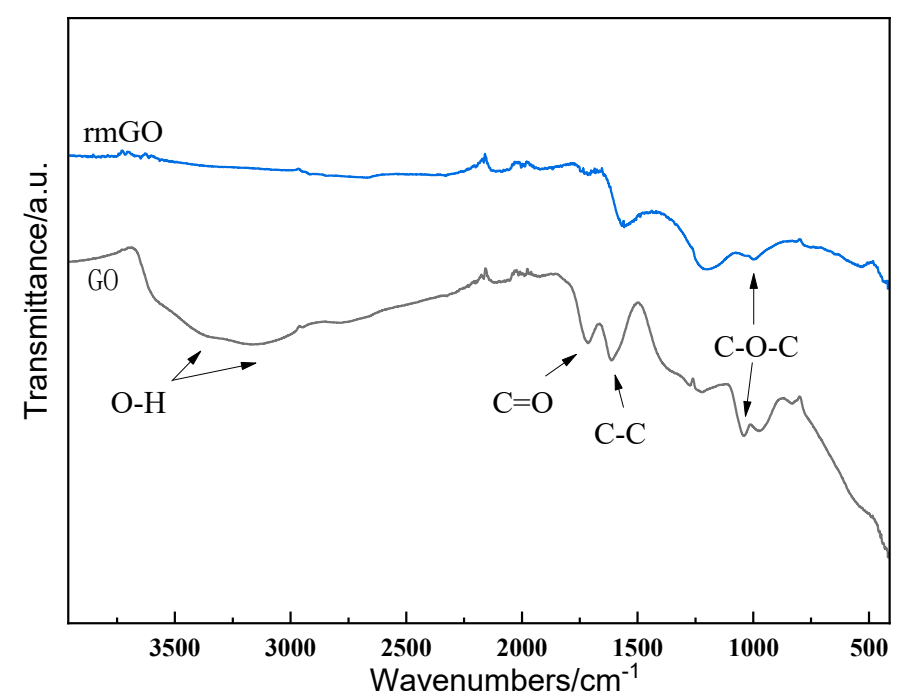

Figure 1. FTIR of GO and mrGO.

\subsection{Characterizations}

Pure aluminum powder and the mixed powder were analyzed by scanning electron microscopy (SEM; SSX-550, Shimadzu Corporation, Kotyo, Japan) coupled by energy dispersive X-ray spectroscopy (EDS). TEM (Transmission electron microscopy) was using to observe the graphene morphology. The tribological properties of the composites were measured using a MMW-1A configuration control universal wear testing machine (Jinan Yihua Friction Testing Technology Co., Ltd., Jinan, China) with a pin-on-disc apparatus, and 
friction pair and the disc are \#45 steel and the mrGO-Cu/ $\mathrm{Al}$ composites disk, respectively. The samples with size of $65 \mathrm{~mm} \times 28 \mathrm{~mm} \times 2.5 \mathrm{~mm}$ were polished with \# 2000 sandpaper and treated by ultrasonic vibration in alcohol before wear test. The disc with hardness of HRC55 62, diameter of $30 \mathrm{~mm}$ and $\mathrm{Ra}=3.2 \mu \mathrm{m}$ was spun perpendicular to the sample surface, and the schematic diagram is shown in Figure 2. The friction and wear test was performed in an unlubricated condition under a load of $20 \mathrm{~N}$ with a rotation speed of $40 \mathrm{rpm}$. Friction coefficient is a function of friction time, which can be observed directly from the computer. The wear and friction coefficient experiment was carried out 3 times for each graphene content, and the results were averaged. After the test, the morphology of the worn surface was analyzed by scanning electron microscopy and EDS.

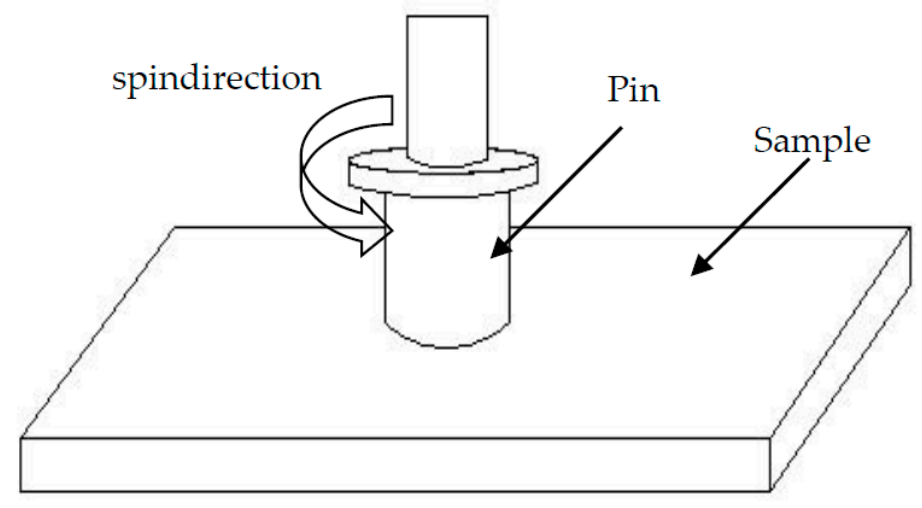

Figure 2. Schematic diagram of wear tests.

\section{Result and Discussion}

\subsection{Microstructure of Composites}

The morphology of the composite powder was observed by SEM and TEM to explore the distribution of mrGO-Cu and the state of copper particles on mrGO surface.

Figure 3a shows SEM images of the pure aluminum powder with $2 \%$ content of mrGO-Cu. It can be seen that the pure aluminum powder has smooth surface with good dispersion. Figure $3 \mathrm{~b}$ is the surface morphology of mrGO-Cu fabricated by chemical modification. It shows the nano-Cu particles covered on the surface of mrGO. However, the mrGO-Cu aggregated with each other because the connection of $\mathrm{Cu}$ particles or mrGO itself. Figure $3 \mathrm{c}$ is the morphology of mixed composite powder of pure $\mathrm{Al}$ with $2 \%$ content of mrGO-Cu, showing that the aluminum powder was evenly dispersed, but a small amount of aluminum powder agglomerated. Some substances were found on the surface of the aluminum powder, which contains $\mathrm{C}, \mathrm{Cu}$ and $\mathrm{Al}$ elements (inset in Figure 3c). It can be concluded that the substance was mrGO-Cu. The TEM image in Figure $3 \mathrm{~d}$ revealed that the aggregation was relieved and $\mathrm{Cu}$ particles were still coating the RGO surface after the mixing process. Due to the appearance of $\mathrm{Cu}$ coating on $\mathrm{mrGO}$, the presence of $\mathrm{Cu}$ represents the location of mrGO.

Figure 4 was the microstructure morphology of mrGO-Cu/Al composite. From Figure 4a, there was no $\mathrm{Al}_{2} \mathrm{Cu}$ precipitate in $\mathrm{Al}$ particles, which means that $\mathrm{Cu}$ is either distributed at the boundary or the solute in $\mathrm{Al}$ matrix. No aggregation of graphene was observed in Figure $4 b$, showing that the chemical modified mrGO-Cu (in Figure $3 b$ ) was exfoliated by the sheer force during the mixing process. The element distribution of $\mathrm{Al}$ and $\mathrm{Cu}$, inserted in Figure $4 \mathrm{~b}$, shows that the content of $\mathrm{Cu}$ is increased while the content of $\mathrm{Al}$ is decreased. It is revealed that $\mathrm{Cu}$ was distributed uniformly around the boundary of $\mathrm{Al}$ particles. It can thus be regarded as the mrGO positions, considering that the mrGO was coated by $\mathrm{Cu}$ particles. 


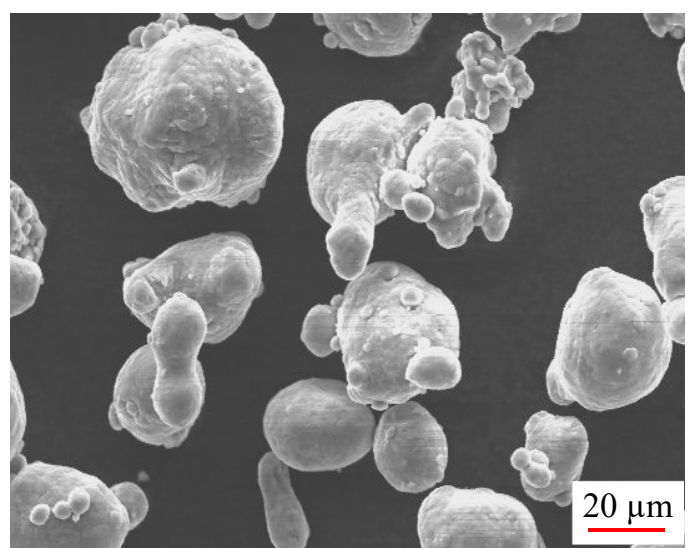

(a)

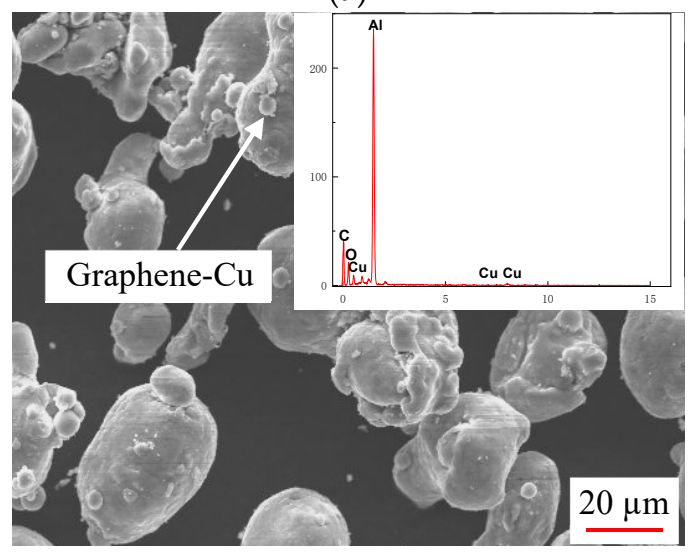

(c)

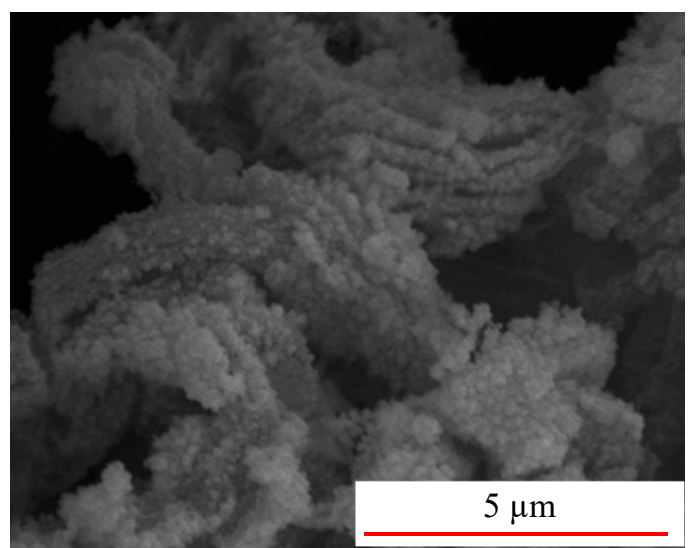

(b)

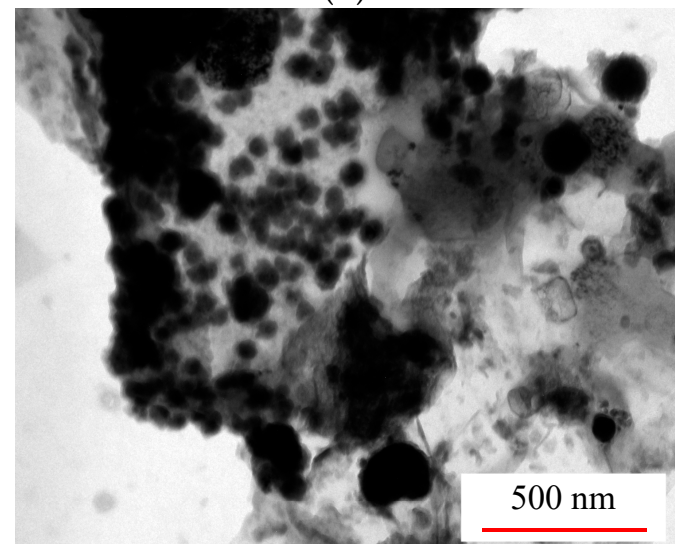

(d)

Figure 3. SEM images of (a) aluminum powder, (b) mrGO-Cu, (c) mixed composite powder and (d) mrGO-Cu after mixing.

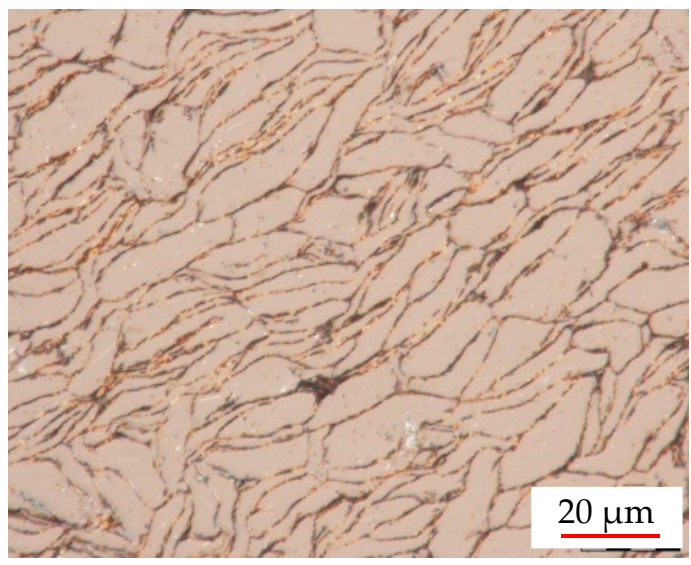

(a)

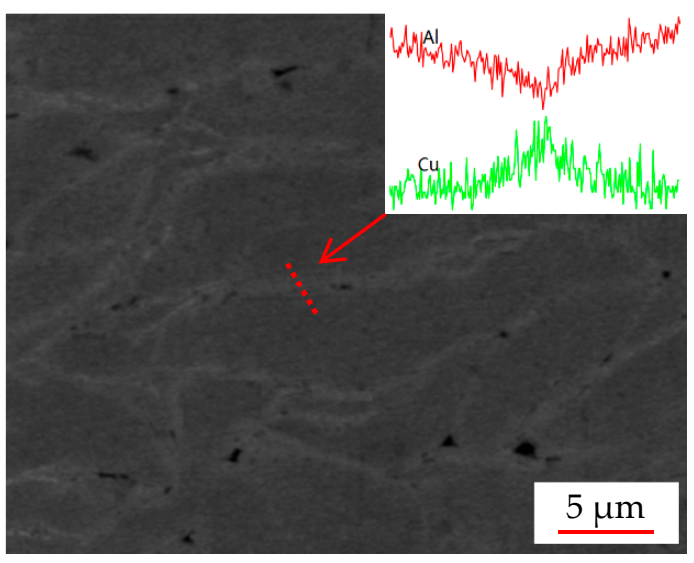

(b)

Figure 4. (a) Optical photomicrograph of mrGO-Cu/Al matrix composite, (b) SEM image of mrGO-Cu/Al matrix composite (insert is element distribution).

\subsection{Tribological Properties of Multilayer mrGO-Cu/Al Matrix Composites}

The friction factor of the composite with different mrGO-Cu contents is shown in Figure 5. Compared with the pure aluminum substrate, the friction coefficient of aluminum composites is decreased with the addition of mrGO-Cu content. It could be seen that the friction coefficient of mrGO-Cu/Al composites obviously decreased when the treatment time for wearing was $25 \mathrm{~min}$. Moreover, $1 \%$ content of mrGO-Cu can cause significantly dropping of the friction coefficient from 0.66 to 0.55 for the composites. When the content 
of mrGO-Cu was up to $4 \%$, the friction coefficient of mrGO-Cu/Al composites reached 0.47 with a reduction of $28.8 \%$ compared to friction coefficient of pure aluminum matrix. The regular pattern was caused by the graphene lubrication film formed on the interface of friction pair. On one hand, the graphene lubrication film could change the mode from unlubrication friction to boundary friction. On the other hand, it could easily access the cavity of composites and decrease the roughness of friction surface, since graphene has a thin thickness. Therefore, there was a tendency towards decrease in the friction coefficient.

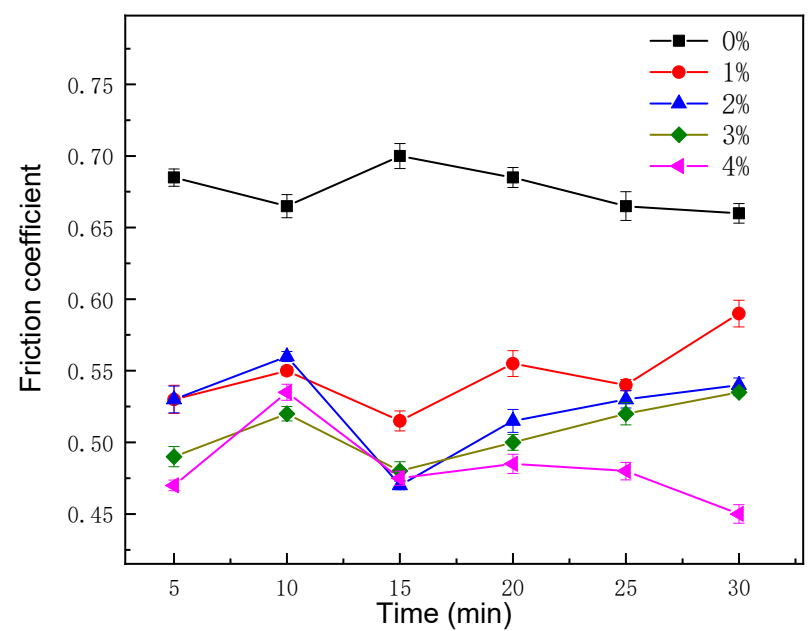

Figure 5. Friction factor of the composite with different mrGO-Cu contents.

\subsection{Effect of the Content of mrGO-Cu on Wear Loss}

Wear loss of the composites with different contents of mrGO-Cu is presented in Figure 6. It could be found that the wear loss of mrGO-Cu/Al composites obviously decreased with the addition of mrGO-Cu. When the content of mrGO-Cu was up to $4 \%$, the value of wear loss of composites ( 0.17 ) is the lowest, which is only $50 \%$ compared to that of pure aluminum matrix (0.34). The mrGO-Cu played a dispersion strengthening effect in the matrix alloy of the composite material. As the content of mrGO-Cu increased, the grain size of the composite material was refined and the hardness increased, the wear resistance of the material was improved. The wear loss of mrGO-Cu/Al composites decreased with the addition of mRGO-Cu may be interpreted as mrGO-Cu could form a lubricating film, and could hinder plastic flow of mrGO-Cu/Al composites, hence reducing plastic deformation and forming smaller scales flakes.

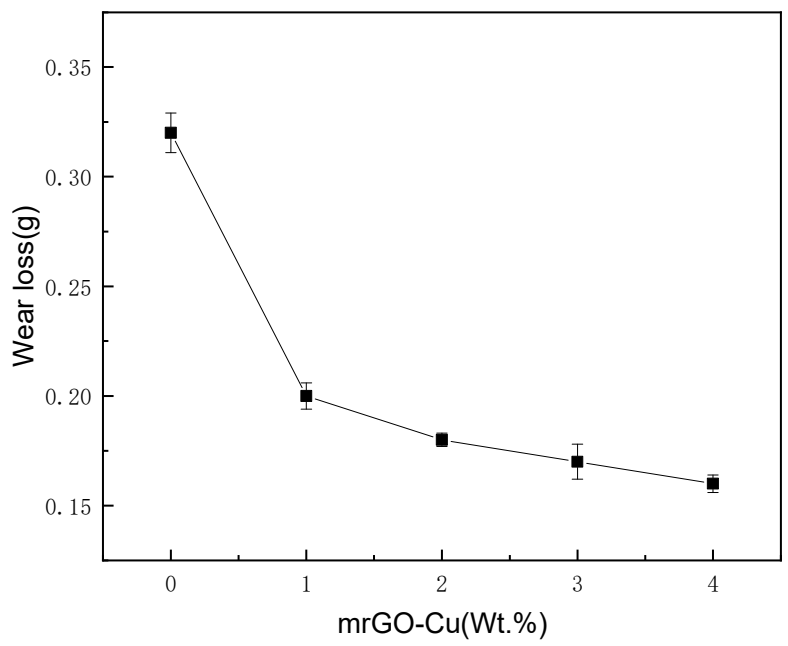

Figure 6. Wear loss of the composites with different contents of mrGO-Cu. 


\subsection{Effect of the Content of mrGO-Cu on Abrasion Mechanism}

SEM results with EDS analysis (Figure 7) were conducted on the worn surface of the mrGO-Cu/Al composites with 2 wt.\% mrGO-Cu. It can be seen that the worn surface consists of $\mathrm{Al}$, oxygen and copper elements. Research has shown that $\mathrm{Al}_{2} \mathrm{O}_{3}$ could easily be produced during the wear process. Therefore, it can be speculated that the white particles, as shown in Figure $7 \mathrm{a}$, are mRGO-Cu and $\mathrm{Al}_{2} \mathrm{O}_{3}$. The presence of Fe (Figure $7 \mathrm{~b}$ ) was caused by grinding of $\# 45$.

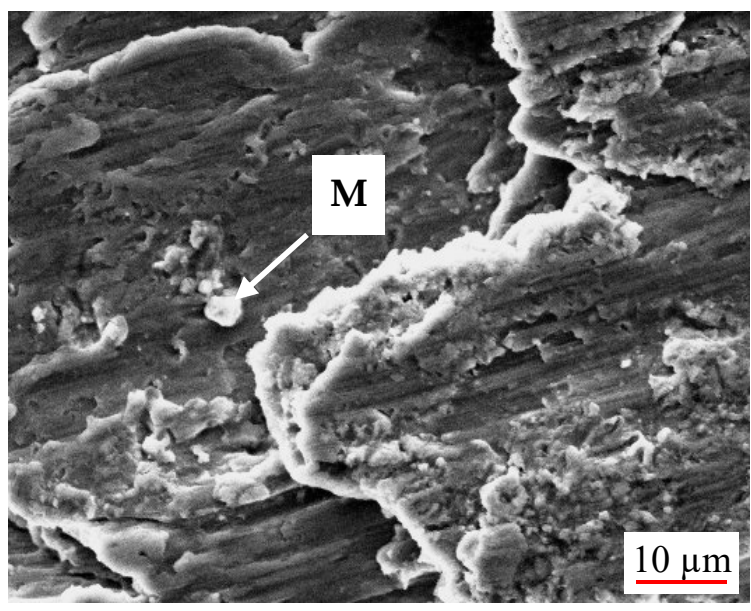

(a)

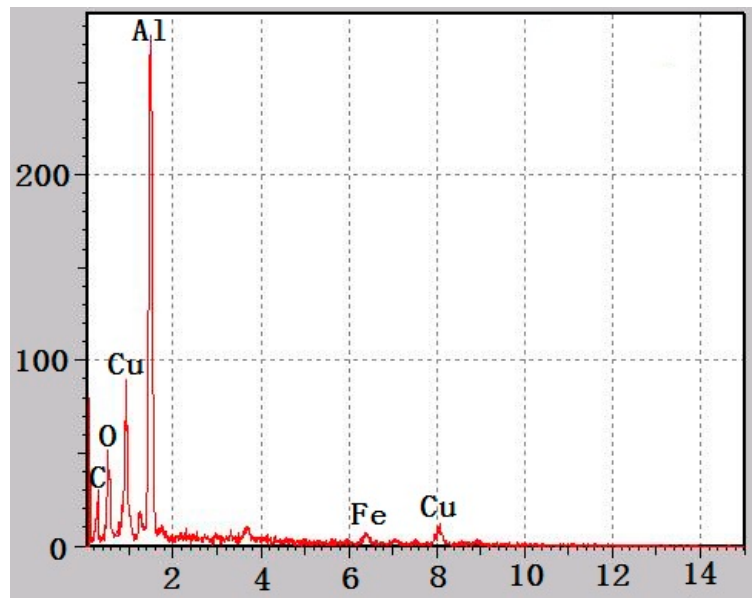

(b)

Figure 7. (a) SEM image of the composite worn surface, (b) Energy spectrum analysis of point M in (a).

The worn surface morphologies of the sample with mrGO-Cu contents of 0 and $3 \mathrm{wt} . \%$ under the same conditions of friction are presented in Figure 8. On the surface of pure aluminum substrate it was possible to observe slipping, exfoliation, delamination and slight furrow as seen in Figure 8a. The friction behavior of high-speed motion produced a large amount of friction heat to soften the matrix alloy and caused adhesive wear, and the composite material was seriously worn [28]. Exfoliation and delamination are the typical adhesive wear morphologies. Oxide film on the matrix surface would be fractured under the effect of shear flow stress. Fracture process exposes the fresh metal in this case, the adhesive wear occurs with the direct contact of the two pure metal surfaces. Both broken oxide film and adhesive wear debris existed on the friction surface leading to slightly wear furrows. Therefore, adhesive wear and abrasive wear presented on the wear process [29]. In addition, the harder roughness of steel surface could also take some roles in the wear furrows owing to the indentation into the soft aluminum surface.

Compared to the morphology of pure aluminum substrate in Figure 8a, the wear morphology of sample with 3 wt.\% mrGO-Cu shown in Figure $7 \mathrm{~b}$ is smoother. Carbon element distribution analysis of samples in Figure 8a,b is shown in Figure 8c,d, respectively. From Figure $8 d$, it can be seen that as the sample with mrGO-Cu content of $3 \%$, the graphene is fulfilled on the wear surface and tends to form a graphene film during the wear process. It may be interpreted by two reasons. Firstly, the multi-graphene layer was delaminated and transferred to the surface as multi-graphene has lower shear force. Secondly, graphene-Cu could be extruded by the plastic deformation force of $\mathrm{Al}$ substrate, thus the wear surface was covered by grapheme [30]. Because graphene film has an excellent self-lubricating property, the existence of graphite lubricating film made adhesive wear behavior weaken. Furthermore, mrGO-Cu nanosheets can inhibit the propagation of material cracks and reduce wear caused by pressure [31,32]. The large peeling sheets were almost invisible on the wear surface.

From Figure $8 \mathrm{~b}$, wide furrows and some debris can be found on the wear surface, indicating that although mrGO-Cu can be used as a lubricating film. However, the multigraphite is modified by copper, both $\mathrm{Cu}$ and $\mathrm{CuO}$, as micro-abrasive grains, could cut the 
soft $\mathrm{Al}$ substrate, and contributed to aggravating abrasive wear. At this stage, the abrasion mechanism was mainly abrasive wear.

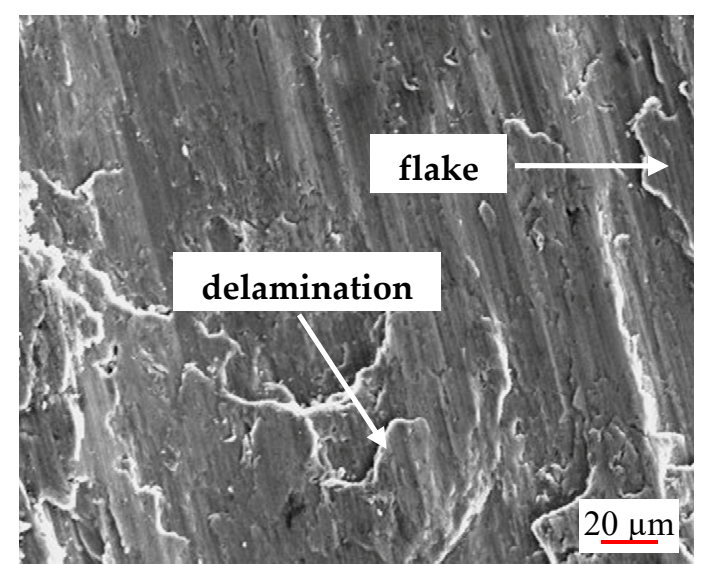

(a)

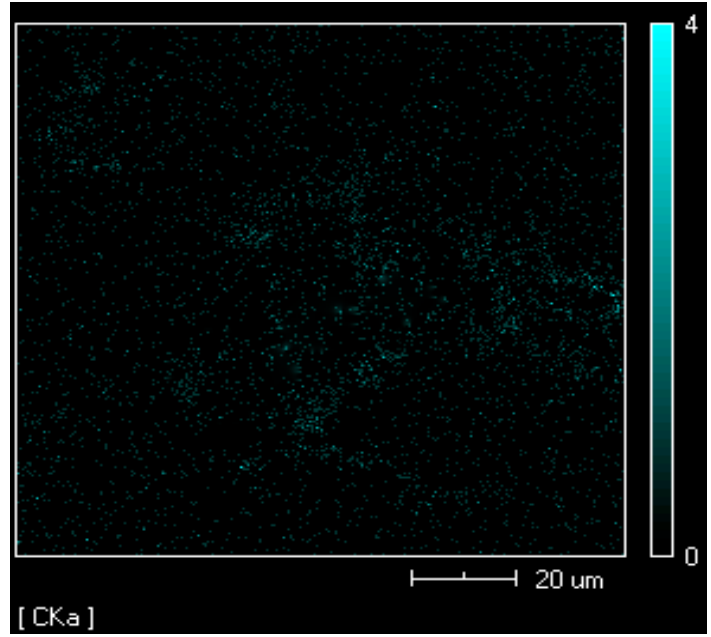

(c)

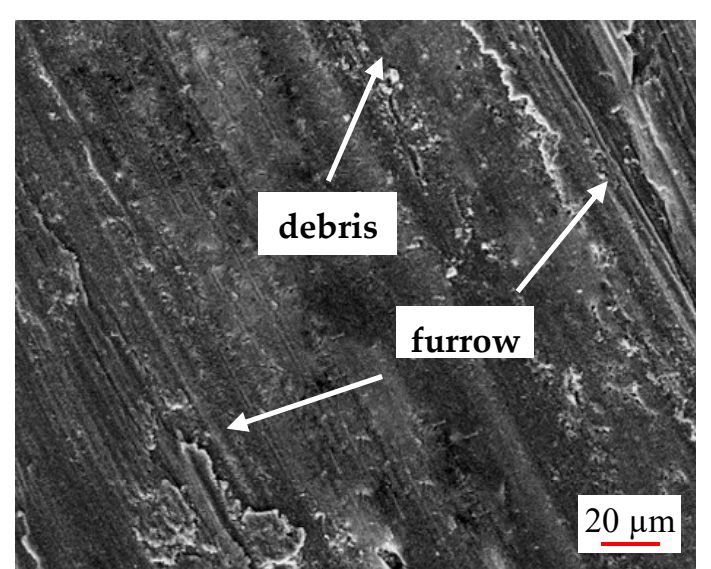

(b)

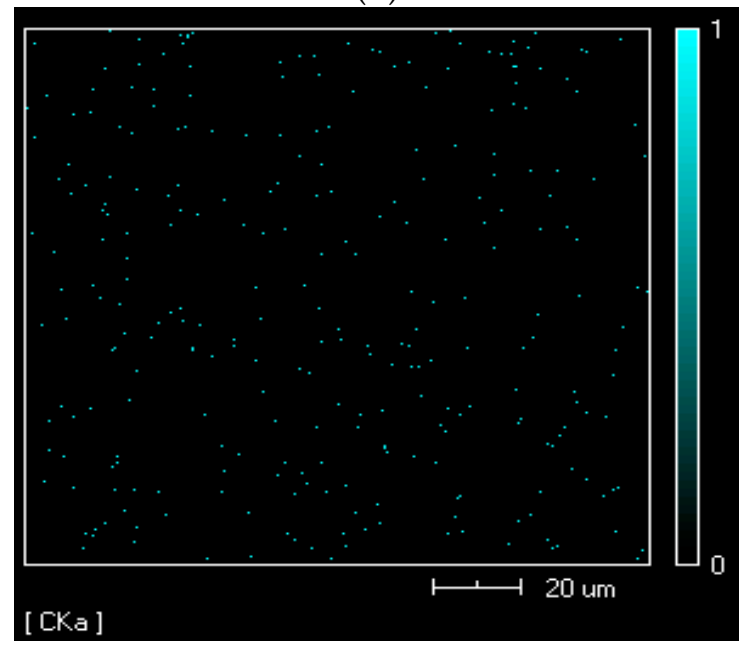

(d)

Figure 8. EDX images of worn surface with different mrGO-Cu contents (a) Al matrix, (b) 3 wt.\% mrGO-Cu/ $\mathrm{Al}$, (c) Surface scanning image of worn surface of Al matrix, (d) Surface scanning image of worn surface of 3 wt.\% mrGO-Cu/Al.

\section{Conclusions}

Multilayer reduced graphene oxide was chemically modified by electroless plating $\mathrm{Cu}$, and mrGO-Cu/Al composite was successfully fabricated through clad rolling of milled powder. The enhanced tribological properties of composites have been summarized as follows:

The graphene lubrication film could change the mode from unlubrication friction to boundary friction. With the increase in graphene content, the friction coefficient of composite materials gradually decreased. The decrement was obvious at a lower content of mrGO-Cu. Friction coefficient of the composite with $4 \%$ of mrGo-Cu could reduce by $28.8 \%$, and the wear loss of the composite reduced by $50 \%$ compared to pure aluminum.

The mrGO-Cu played an important role of dispersion strengthening in the aluminum matrix. As the content of mrGO-Cu increased, the grain size of the composite material was refined and the hardness increased, the wear resistance of the material was improved. The wear loss of mrGO-Cu/Al composites decreased with the addition of mrGO-Cu.

Under the action of shear force, the mrGO-Cu was unfolded at the wear interface. The mrGO-Cu can form a graphite lubricating film and thus reduce the adhesive wear. Wear mechanism was also dominated by adhesive wear into abrasive wear with the addition of mrGO-Cu. 
Author Contributions: Conceptualization, R.G. and F.L.; methodology, F.L.; formal analysis, F.L.; writing-review and editing, F.L., N.S. and R.G.; project administration, R.G.; funding acquisition, R.G. All authors have read and agreed to the published version of the manuscript.

Funding: This research was funded by National Natural Science Foundation of China (No. 51871184).

Institutional Review Board Statement: Not applicable.

Informed Consent Statement: Not applicable.

Data Availability Statement: Data sharing not applicable.

Acknowledgments: The authors would like to thank Yang Yuanquan for his suggestions to improve the quality of our manuscript.

Conflicts of Interest: The authors declare no conflict of interest.

\section{References}

1. Ma, K.; Wen, H.; Hu, T.; Topping, T.D.; Isheim, D.; Seidman, D.N.; Lavernia, E.J.; Schoenung, J.M. Mechanical behavior and strengthening mechanisms in ultrafine grain precipitation-strengthened aluminum alloy. Acta Mater. 2014, 62, 141-155. [CrossRef]

2. Mazahery, A.; Shabani, M.O. Nano-sized silicon carbide reinforced commercial casting aluminum alloy matrix: Experimental and novel modeling evaluation. Powder Technol. 2012, 217, 558-565. [CrossRef]

3. Farahani, M.V.; Emadoddin, E.; Emamy, M.; Raouf, A.H. Effect of grain refinement on mechanical properties and sliding wear resistance of extruded Sc-free 7042 aluminum alloy. Mater. Des. 2014, 54, 361-367. [CrossRef]

4. Mazahery, A.; Shabani, M.O. Influence of the hard coated B4C particulates on wear resistance of Al-Cu alloys. Compos. Part. B Eng. 2012, 431, 1302-1308. [CrossRef]

5. Yang, J.B.; Lin, C.B.; Wang, T.C.; Chu, H.Y. The tribological characteristics of A356.2Al alloy/Gr(p) composites. Wear 2004, 257, 941-952. [CrossRef]

6. Ramesh, C.S.; Adarsha, H.; Pramod, S.; Khan, Z. Tribological characteristics of innovative Al6061-carbon fiber rod metal matrix composites. Mater. Des. 2013, 50, 597-605. [CrossRef]

7. Manikandan, P.; Sieh, R.; Elayaperumal, A.; Le, H.R.; Basu, S. Micro/Nanostructure and Tribological Characteristics of Pressureless Sintered Carbon Nanotubes Reinforced Aluminium Matrix Composites. J. Nanomater. 2016. [CrossRef]

8. Novoselov, K.S.; Fal, V.I.; Colombo, L.; Gellert, P.R.; Schwab, M.G.; Kim, K. A roadmap for graphene. Nature 2012, 490, 192-200. [CrossRef]

9. Xiang, Q.J.; Yu, J.G.; Jaroniec, M. Graphene-based semiconductor photocatalysts. Chem. Soc. Rev. 2012, 41, 782-796. [CrossRef]

10. Zhu, Y.; Murali, S.; Cai, W.; Li, X.; Suk, J.W.; Potts, J.R.; Ruoff, R.S. Graphene and Graphene Oxide: Synthesis, Properties, and Applications. Adv. Mater. 2010, 22, 3906-3924. [CrossRef]

11. Stankovich, S.; Dikin, D.A. Carbon sheet solutions. Nature 2006, 442, 282-286. [CrossRef]

12. Dean, C.R.; Young, A.F.; Meric, I.; Lee, C.; Wang, L.; Sorgenfrei, S.; Watanabe, K.; Taniguchi, T.; Kim, P.; Shepard, K.L.; et al. Boron nitride substrates for high-quality graphene electronics. Nat. Nanotechnol. 2010, 5, 722-726. [CrossRef] [PubMed]

13. Berman, D.; Erdemir, A.; Sumant, A.V. Few layer graphene to reduce wear and friction on sliding steel surfaces. Carbon 2013, 54, 454-459. [CrossRef]

14. Marchetto, D.; Held, C.; Hausen, F.; Wählisch, F.; Dienwiebel, M.; Bennewitz, R. Friction and Wear on Single-Layer Epitaxial Graphene in Multi-Asperity Contacts. Tribol. Lett. 2012, 48, 77-82. [CrossRef]

15. Berman, D.; Erdemir, A.; Sumant, A.V. Graphene: A new emerging lubricant. Mater. Today 2014, 17, 31-42. [CrossRef]

16. Lin, J.S.; Wang, L.W.; Chen, G.H. Modification of Graphene Platelets and their Tribological Properties as a Lubricant Additive. Tribol. Lett. 2011, 41, 209-215. [CrossRef]

17. Wang, H.; Xie, G.; Zhu, Z.; Ying, Z.; Zeng, Y. Enhanced tribological performance of the multi-layer graphene filled poly(vinyl chloride) composites. Compos. Part A Appl. 2014, 67, 268-273. [CrossRef]

18. Belmonte, M.; Ramírez, C.; González-Julián, J.; Schneider, J.; Miranzo, P.; Osendi, M.I. The beneficial effect of graphene nanofillers on the tribological performance of ceramics. Carbon 2013, 61, 431-435. [CrossRef]

19. Jian, X. The Study on Mechanical Properties and Friction and Wear Properties of Filled PTFE Composites; Shanghai Jiaotong University: Shanghai, China, 2013.

20. Zhang, Y. Study on the Graphene/Silicon Nitride Based Composite Ceramic Tools and Their Friction and Wear Properties; Qilu University: Jinan, China, 2017.

21. Yan, S.J.; Dai, S.L.; Zhang, X.Y.; Yang, C.; Hong, Q.H.; Chen, J.Z.; Lin, Z.M. Investigating aluminum alloy reinforced by graphene nanoflakes. Mater. Sci. Eng. A 2014, 612, 440-444. [CrossRef]

22. Pérez-Bustamante, R.; Bolaños-Morales, D.; Bonilla-Martínez, J.; Estrada-Guel, I.; Martínez-Sánchez, R. Microstructural and hardness behavior of graphene-nanoplatelets/aluminum composites synthesized by mechanical alloying. J. Alloy Compd. 2014, 615, S578-S582. [CrossRef]

23. Xu, Z.; Shi, X.; Zhai, W.; Yao, J.; Song, S.; Zhang, Q. Preparation and tribological properties of TiAl matrix composites reinforced by multilayer graphene. Carbon 2014, 67, 168-177. [CrossRef] 
24. Nethravathi, C.; Rajamathi, M. Chemically modified graphene sheets produced by the solvothermal reduction of colloidal dispersions of graphite oxide. Carbon 2008, 46, 1994-1998. [CrossRef]

25. Luo, J.; Jiang, S.; Zhang, H.; Jiang, J.; Liu, X. A novel non-enzymatic glucose sensor based on Cu nanoparticle modified graphene sheets electrode. Anal. Chim. Acta 2012, 709, 47-53. [CrossRef]

26. Xiong, Z.G.; Zhang, L.L.; Zhao, X.S. Visible-Light-Induced Dye Degradation over Copper-Modified Reduced Graphene Oxide. Chem. Eur. J. 2011, 17, 2428-2434. [CrossRef]

27. Zhao, Z.Y.; Guan, R.G.; Guan, X.H.; Feng, Z.X.; Chen, H.; Chen, Y. Microstructures and Properties of Graphene-Cu/Al Composite Prepared by a Novel Process Through Clad Forming and Improving Wettability with Copper. Adv. Eng. Mater. 2015, 17, 663-668. [CrossRef]

28. Shi, X.L. Study on Tribological Performance of Ni Al Matrix Self-Lubricating Composite with Addition of Graphene; Wuhan University of Technology: Wuhan, China, 2016.

29. Suresha, S.; Sridhara, B.K. Wear characteristics of hybrid aluminium matrix composites reinforced with graphite and silicon carbide particulates. Compos. Sci. Technol. 2010, 70, 1652-1659. [CrossRef]

30. Ames, W.; Alpas, A.T. Wear mechanisms in hybrid composites of graphite-20 Pct SiC in A356 aluminum alloy (Al-7 Pct Si-0.3 Pct Mg). Metall. Mater. Trans. A 1995, 26, 85-98. [CrossRef]

31. Vencl, A.; Vučetić, F.; Bobić, B.; Pitel, J.; Bobić, I. Tribological characterisation in dry sliding conditions of compocasted hybrid A356/SiC p/Gr p composites with graphite macroparticles. Int. J. Adv. Manuf. Technol. 2019, 100, 2135-2146. [CrossRef]

32. Kvetková, L.; Duszová, A.; Hvizdoš, P.; Dusza, J.; Kun, P.; Balázsi, C. Fracture toughness and toughening mechanisms in graphene platelet reinforced $\mathrm{SiN}_{4}$ composites. Scr. Mater. 2012, 66, 7793-7796. [CrossRef] 